\title{
Spatial Distributions of Humic Substances and Evaluation of Sediment Organic Index on Lake Dalinouer, China
}

\author{
Dekun Hou, ${ }^{1,2}$ Jiang He, ${ }^{1,2,3}$ Changwei Lü,, ${ }^{2,3}$ Wei Wang, ${ }^{2,3}$ and Fujin Zhang \\ ${ }^{1}$ College of Life Sciences of Inner Mongolia University, University West Road No. 235, Saihan District, Hohhot, \\ Inner Mongolia 010021, China \\ ${ }^{2}$ College of Environment \& Resources, Inner Mongolia University, University West Road No. 235, Saihan District, Hohhot, \\ Inner Mongolia 010021, China \\ ${ }^{3}$ Institute of Environmental Geology, College of Environment \& Resources, Inner Mongolia University, University West Road No. 235, \\ Saihan District, Hohhot, Inner Mongolia 010021, China \\ ${ }^{4}$ Institute of Environmental Resources and Analytical Technique, Inner Mongolia Academy of Agricultural and Animal Husbandry \\ Sciences, Hohhot 010031, China
}

Correspondence should be addressed to Jiang He; ndjhe1958@yeah.net

Received 14 May 2013; Accepted 19 August 2013; Published 2 January 2014

Academic Editors: F. Brandt, A. Garralón, P. S. Hooda, M. Jang, B. Ouddane, and F. Tassi

Copyright ( 2014 Dekun Hou et al. This is an open access article distributed under the Creative Commons Attribution License, which permits unrestricted use, distribution, and reproduction in any medium, provided the original work is properly cited.

The aim of this study is to examine and interpret the spatial distribution of sedimentary humic substances in Lake Dalinouer. Humic substances in sediments were analyzed separately in different fractions: humins (HM), humic acid (HA), fulvic acid (FA), and different forms of organic carbon. The results showed that total organic carbon (TOC) contents varied from 7.25 to $65.54 \mathrm{~g} \mathrm{~kg}^{-1}$ with a mean of $36.37 \pm 17.74 \mathrm{~g} \mathrm{~kg}^{-1}$. It was found that high TOC concentrations were at lake's center and low TOC concentrations occurred at the estuary of inflows. Different redox conditions caused by water depth were of the most important factors which might influence TOC contents. Concentrations of HM, HA, and FA in sediments were detected in range of $6.40-58.16 \mathrm{~g} \mathrm{~kg}^{-1}, 0.27-$ $3.50 \mathrm{~g} \mathrm{~kg}^{-1}$, and $0.27-4.26 \mathrm{~g} \mathrm{~kg}^{-1}$, respectively. Of them, HM was the dominant form and accounted for 74-94\% of TOC and 80-90\% of humus. Organic Sediment Index (OSI) was used to assess the organics accumulation, and the value of OSI ranged from 0.001 to 0.30 , which indicated that Lake Dalinouer was relatively clean. The relative high degree of humidification was found in the eastern of lake, where it should be taken into consideration seriously.

\section{Introduction}

Natural organic matter (NOM) is present throughout the ecosystem and plays a critical role within several natural and anthropogenic processes, such as the global carbon geochemical cycle and the transport of organic and inorganic pollutants across the environmental compartments [1-3]. Among organic matter, humic substances considered to the major NOM constituent in soil and water as well as in geological organic deposits such as lake sediments, largely affect these processes. In sediments, humic substances, account for $60-75 \%$ of the total NOM [4], being recognized as the most persistent reservoir of sedimentary organic carbon with a mean residence time of several hundred years, and therefore involved in the control of $\mathrm{CO}_{2}$ emission to the atmosphere, being a relevant carbon sink $[1,5,6]$. These fairly stable and extremely complex copolymers have received a great deal of interest due to their active participation in biogeochemical processes.

The source of organic matter presents in soils, and sediments are mainly plants and animals residues, which, after extensive postdepositional microbiological and chemical transformations, become a natural polymeric material known as humic substances (HS) [3, 4]. The products formed tend to associate with complex chemical structures that are normally more stable than the starting materials. Generally, 
HS are considered as a series of relatively high-molecularweight, brown to black colored substances formed by secondary synthesis reactions [7]. Important characteristics of HS are the ability to form complexes with metal ions and hydrous oxides and interact with clay minerals and organic compounds such as alkanes, fatty acids, dialkyl phthalates, and pesticides. In fact HS have a variety of functional groups [8] and can form strong complexes with metal ions, affecting their speciation, mobilization, and toxicity $[9,10]$. The interaction of HS with oxide and clay minerals can modify their physicochemical characteristics and affect the way that these substances interact with water, metal ions, and other organic molecules $[11,12]$. Traditionally, methods to separate HS from soil and sedimentary matrices have relied on their solubility in acid and alkaline solutions that differentiate HS in three main fractions: the humic acid (HA), soluble in alkali but insoluble in acid; the fulvic acid (FA), soluble in both alkali and acid solutions; and the humins (HM), an insoluble fraction [6, 7]. The humic chemistry, analytical methods, and structural models in soil and sediment are comprehensively discussed in [13].

A number of studies have shown that HS are very complex and heterogeneous molecular systems $[8,14-16]$. This implies the need of using complementary analytical techniques to infer the chemical properties of such substances; elemental analysis and in particular the $\mathrm{H} / \mathrm{C}$ and $\mathrm{C} / \mathrm{N}$ atomic ratios are frequently used to indicate organic matter source, degree of condensation, and the environmental conditions under which the HS were generated [8, 17, 18]. However, more detail characterization of HS is required, and other analytical techniques used are infrared, ultraviolet visible and fluorescence spectroscopy [19-22], carbon isotopic analysis [23-25], thermal analysis and analytical pyrolysis [26-28], wet chemistry techniques [29], nuclear magnetic resonance techniques, and so forth.

Lake sediments reflect processes in the catchment area (e.g., runoff, atmospheric deposition, soil weathering, etc.) and in the water column (e.g., dissolution, sorption, precipitation, etc.). They act as a major repository as well as a potential source of water pollutants, that is, heavy metals and persistent organics [30-32]. Organic matters in sediments play an important role in the accumulation and bioavailability of pollutants, especially metals, and have a significant effect on the migrating and transforming course of pollutants at sediments-water interface. As the major components of the sedimentary organic matter (SOM), humic matters contain both variety of constant or trace elements and simple organic compounds which were the important source of mineral nutrition and organic nutrition, meanwhile humic matters are also one of the important energy source of some certain microorganisms in the soil. Consequently, despite the environmental relevance of HS, many aspects of their formation, functions, and structural compositions have persisted unknown since first extracted from peat bogs in Germany by Achard [33] in 1786, and the studies on HS have attracted attention. Recent researches in HS and NOM in China produced significant contributions to the advance of knowledge in this discipline [34]. Till now, the studies mainly focused on either the content distribution or the composition characteristics of HS in forest, farmland, grassland, and wetland [35-37], but no much information was available about HS in lake sediments. An adequate knowledge of the spatial distribution and chemical structure of HS from sedimentary systems is of interest to better understand a number of processes occurring in nature. In this study, we investigated the spatial distribution and proportion of the different HS fractions as well as a number of other chemical characteristics of the surface sediments from the Lake Dalinouer.

\section{Material and Methods}

2.1. Study Area. The Dalinouer Lake (E $116^{\circ} 25^{\prime} \sim 116^{\circ} 35^{\prime}, \mathrm{N}$ $45^{\circ} 13^{\prime} \sim 45^{\circ} 23^{\prime}$ ), a closed shallow lake with an area of $\sim 238 \mathrm{~km}^{2}$ and a mean depth of $7 \mathrm{~m}$, is located at the semiarid continental steppe zone with an annual precipitation of 150-300 mm and an annual average evaporation of $1600-1800 \mathrm{~mm}$. The regional zonal vegetation was mainly steppe with localized sedge meadows developed in the humid riverbank and lake shore. The lake was fed insufficiently by Gong Geer River, Liangzi River, Haolai River, and Shali River from its northeast and southwest. As a consequent of continental climate and human activity, the lake water evolved into the $\mathrm{Mg}^{2+}-\mathrm{Cl}^{-}$$\mathrm{HCO}_{3}{ }^{-}$type with a high $\mathrm{pH}$ values that ranged from 9.1 to 9.8 and mean alkalinity of $53.57 \mathrm{mmol} \mathrm{L}^{-1}$. Recently, environmental and ecological problems in the Dalinouer Lake that include a decline in water level, shrinking area, increasing salinity, and increasing eutrophication are of more and more concern and become a focus area for environmental studies.

2.2. Sediment Sampling. Locations of sampling sites in the Lake Dalinouer (Figure 1) were set according to the standard methods from Lake Ecosystem Observation Method [38]. The samples were taken in July 2009; shallow water sediments ( $\leq 4 \mathrm{~m}$ ) were sampled using a $\mathrm{KC}$ mod A och B (Swedaq Company, Norway), while deeper sediments $(>4 \mathrm{~m}$ ) were sampled using SA Beeker (Eijkelkamp, The Netherlands). Sediments $(0-10 \mathrm{~cm}$ depth) were collected and quickly packed in air tight polythene bags. In addition, sediment cores collected from sites DLNE-3 and DLNE- 8 and were sectioned at $2 \mathrm{~cm}$ interval after the overlying water was siphoned, and similarly the samples were placed into sealed polyethylene bags transported to the laboratory for storage at $-20^{\circ} \mathrm{C}$, and kept under refrigeration until the analytical determinations. During the sample collection, a global positioning system (GPS) was used to locate the sites. Measurements of temperature, $\mathrm{pH}$, dissolved oxygen, Secchi disc visibility, and depth were recorded in situ while sampling. Prior to laboratory analysis, samples were air-dried at room temperature, ground with a mortar and pestle, and sieved with stainless-steel sieve to an adequate size $(<0.2 \mathrm{~mm})$.

2.3. Extraction of Organic Material and Analysis Method. HS were extracted from sediment sample using analytic procedures based on solubility differences in acid and alkaline media [39-41]. In brief, sediment samples (10 g) were 


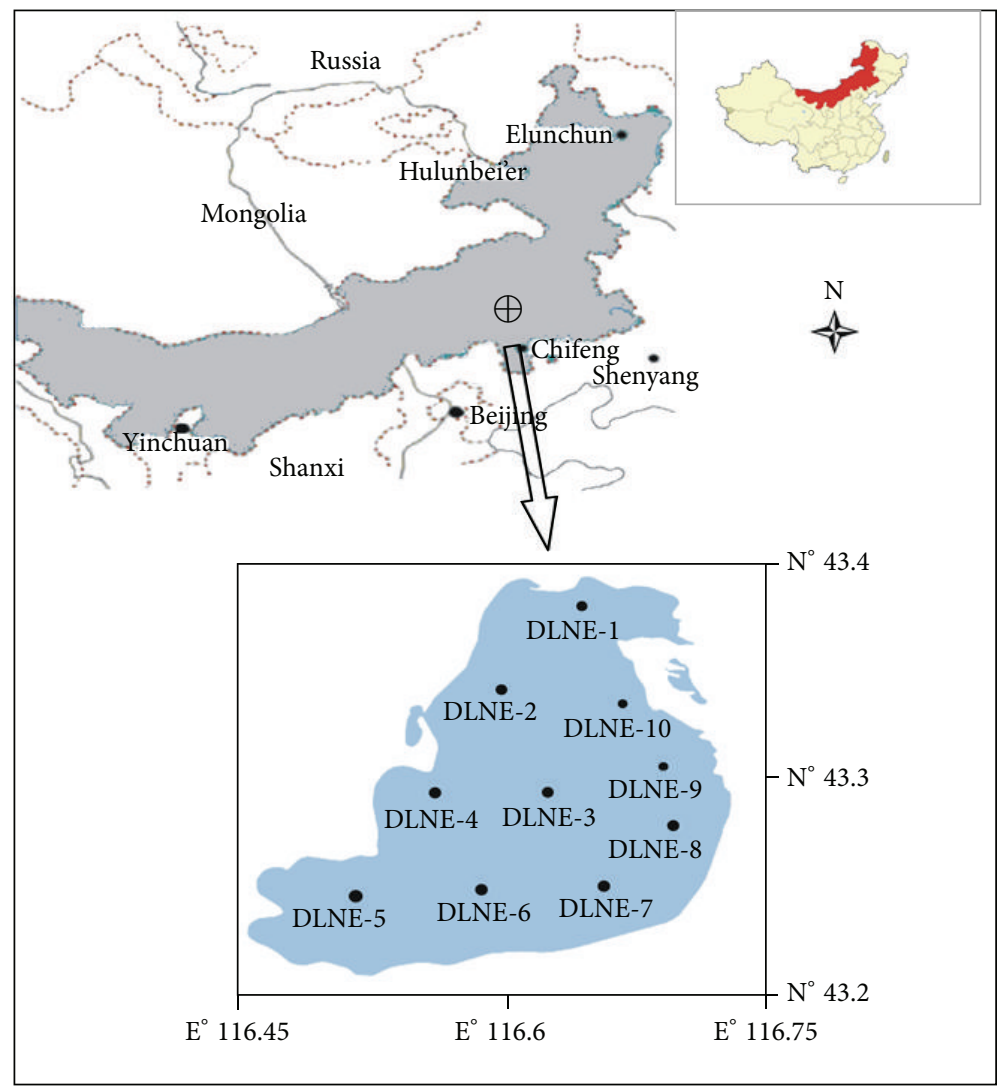

FIGURE 1: Map of Lake Dalinouer showing the locations of sampling sites.

extracted with $100 \mathrm{~mL}$ of a mixture of $\mathrm{NaOH}(0.1 \mathrm{M})$ and $\mathrm{Na}_{4} \mathrm{P}_{2} \mathrm{O}_{7}(0.1 \mathrm{M})$ at room temperature in a conical flask under $\mathrm{N}_{2}$ atmosphere, shaken for $5 \mathrm{~min}$, and then transferred into boiling water bath for 1 hour. The supernatant was separated from the insoluble residue (humins and inorganic components) by centrifugation. After acidification with concentrated $\mathrm{HCl}$ to $\mathrm{pH} \mathrm{1,} \mathrm{the} \mathrm{humic} \mathrm{acids} \mathrm{were} \mathrm{allowed} \mathrm{to}$ precipitate for $24 \mathrm{~h}$ at $4^{\circ} \mathrm{C}$ and separated from the acid-soluble supernatant by centrifugation. After freeze-drying, the humic acids were stored at $4^{\circ} \mathrm{C}$ until analysis; alkaline samples were kept under a nitrogen atmosphere.

The total organic carbon (TOC) content of the sediment was determined by wet chemical combustion and subsequent quantification of $\mathrm{CO}_{2}$ by flow injection analysis (FIA). The organic phosphorus and organic nitrogen were determined as described in $[42,43]$.

2.4. Light Organic Carbon Fraction Separation and Analysis. Light organic carbon fraction was determined using a modification of Janzen and Campbell as described in $[44,45]$. $\mathrm{C}$ in light and heavy fractions was determined previously an extracted with Dichromate Potassium Oxidation. Five grams of air-dried lake sediments were placed in a centrifuge with a $20 \mathrm{~mL}$ sodium iodide (Beijing Chemical works, Beijing, China) solution with density of $1.7 \mathrm{~g} \mathrm{~cm}^{-3}$. The tubes were shaken in a water bath at constant temperature for 2 hours. After a settling period of $30 \mathrm{~min}$, the samples were centrifuged at $4200 \mathrm{rpm}$ for $10 \mathrm{~min}$. The floating light fraction organic carbon was siphoned off with a syringe with a $2 \mathrm{~cm}$ long section of Tygon tubing, and the suspended material was transferred into a filtration unit (a 325 meshes light copper siever). The centrifugation-filter process was repeated at least four times to ensure complete recovery of the carbon light fraction, until no floating material remained, and the composited light fraction materials were washed in $0.01 \mathrm{M}$ $\mathrm{CaCl}_{2}$ solution. The material remaining at the bottom of the test tube (heavy organic carbon fraction) was finally washed onto a separate funnel. Both the light fraction and heavy fraction organic carbon were washed with deionized water and dried for 2 hours for $65^{\circ} \mathrm{C}$. Both fraction, were weighed, ground to a fine powder ( $<200$ meshes), and analyzed for organic carbon analysis by dichromate potassium oxidation.

2.5. Different Forms of Combined Humus and Analysis. The combination forms of humus in lake sediments were measured through a modified Fujiping's method [46, 47]. Typically, a given quantity of $5.0 \mathrm{~g}$ from dry lake sediments which had removed the light organic carbon fraction was placed in a centrifuge tube with a $50 \mathrm{~mL} 0.1 \mathrm{~N} \mathrm{NaOH}$ solution. The tube was shaken by hand for $5 \mathrm{~min}$, incubated overnight at $30^{\circ} \mathrm{C}$ and then centrifuged for $15 \mathrm{~min}$ at $3000 \mathrm{rpm}$. The supernatant is collected and stored in a bottle of polyethylene, and this fraction is supposed to contain loosely combined humus. The residue from the first extraction was treated with $25 \mathrm{~mL} 0.1 \mathrm{~N}$ 
TABLE 1: Physical and chemical parameters of water from the Lake Dalinouer.

\begin{tabular}{|c|c|c|c|c|c|c|}
\hline Sample Sites & $\mathrm{pH}$ & Temperature $\left({ }^{\circ} \mathrm{C}\right)$ & $\mathrm{DO}^{\mathrm{a}}(\mathrm{mg} / \mathrm{L})$ & $\mathrm{WT}^{\mathrm{b}}(\mathrm{cm})$ & $\mathrm{WD}^{\mathrm{c}}(\mathrm{cm})$ & Conductivity $(\mathrm{ms} / \mathrm{cm})$ \\
\hline DLNE-1 & 9.10 & 20.4 & 5.06 & 75 & 200 & 9.39 \\
\hline DLNE-2 & 9.44 & 21.3 & 4.46 & 60 & 500 & 9.44 \\
\hline DLNE-3 & 9.39 & 20.9 & 4.78 & 60 & 800 & 9.45 \\
\hline DLNE-4 & 9.38 & 21.0 & 4.69 & 50 & 700 & 9.47 \\
\hline DLNE-5 & 9.38 & 21.1 & 4.61 & 65 & 900 & 9.45 \\
\hline DLNE-6 & 9.50 & 21.5 & 4.56 & 60 & 650 & 9.44 \\
\hline DLNE-7 & 9.62 & 22.2 & 4.29 & 70 & 300 & 9.41 \\
\hline DLNE-8 & 9.45 & 22.0 & 4.48 & 65 & 350 & 9.43 \\
\hline DLNE-9 & 9.80 & 23.0 & 4.13 & 60 & 650 & 9.47 \\
\hline DLNE-10 & 9.40 & 23.3 & 3.98 & 65 & 350 & 9.46 \\
\hline
\end{tabular}

${ }^{a}$ Dissolved Oxygen.

${ }^{\mathrm{b}}$ Water transparency.

${ }^{\mathrm{c}}$ Water depth.

$\mathrm{NaOH}$ and $25 \mathrm{~mL} 0.1 \mathrm{M} \mathrm{Na}_{4} \mathrm{P}_{2} \mathrm{O}_{7}$ (pH approximately 13), and kept at $30^{\circ} \mathrm{C}$ for 24 hours. Afterwards, the supernatants were separated by centrifugation at $3000 \mathrm{rpm}$ for $15 \mathrm{~min}$, and this fraction contains the stable combined humus. The residues at the bottom of the tube contained the tightly combined humus, this fraction is washed three times with distilled water, and the organic carbon content measured. To avoid cross-contaminate, the tubes were not re-used.

The supernatants above-mentioned were treated with $\mathrm{H}_{2} \mathrm{SO}_{4}\left(0.5 \mathrm{~mol} \mathrm{~L}^{-1}\right)$, and $\mathrm{pH}$ was adjusted to 7 and evaporated to dryness at $80^{\circ} \mathrm{C}$ in a water bath. Finally, the organic carbon in loosely and stably combined humus fractions was estimated through a modified dichromate potassium oxidation method.

2.6. Quality Control and Statistical Analyses. All reagents used are verified to be contaminant-free. All equipment and glassware used to analyze samples are verified to be carbon-free or are previously combusted at $400^{\circ} \mathrm{C}$ for a minimum of 4 hours. All the data collected were subject to strict quality-control procedures. The experiments were carried out by triplicate, and the relative standard deviation was less than $10 \%$. For every set of 10 samples, a method blank (solvent) was used to check interferences. Statistical analyses including mean values, linear and nonlinear fitting were performed with Statistical Program for Social Sciences (SPSS) 13.0 software. Significance levels are reported as not significant $(P>0.05)$ or significant $(P<0.05)$, and the counter maps are drawn with surfer 10.0.

\section{Results and Discussion}

3.1. Limnological Characteristics of the Studied Lake. Basic physical-chemical analyses were made in early fall 2010 to determine the trophic status of the examined lake. Basic physical and chemical parameters of studied lake are shown in Table 1. There were no significant differences in water temperature (varied between $20.4^{\circ} \mathrm{C}$ and $23.3^{\circ} \mathrm{C}$ ), the concentration of dissolved oxygen (from 3.68 to $5.06 \mathrm{mg} \mathrm{L}^{-1}$ ), or $\mathrm{pH}$
(9.1-9.8, mean value 9.5) among water samples collected from Dalinouer Lake. However, Secchi disc visibility, total organic nitrogen, and dissolved organic carbon concentrations fluctuated distinctly in different sample sites. A relatively good synchronization between temperature and dissolved oxygen was seen $\left(R^{2}=0.9247\right)$. As expected, temperature showed a significant inverse relationship with dissolved oxygen. In the present study, average depth of visibility was $63 \mathrm{~cm}$ with maximum of $60 \mathrm{~cm}$ and minimum of $75 \mathrm{~cm}$. Electrical conductance was high but in a narrow range $\left(9.39-9.47 \mathrm{~ms} \mathrm{~cm}^{-1}\right)$ of conductivity. High conductivity values may be due to the increase concentration of dissolved salts from discharge effluents.

Based on examined physicochemical parameters, the studied lake was graded accordingly to progressing degree of eutrophication. The Lake Dalinouer, which had high water transparency and TOC and low DIC concentration, was recognized as a typical oligo/mesotrophic lake, and it fulfilled the criteria of their water trophic status proposed by Champan [48].

3.2. Spatial Distributions of Organic Carbon in Surface Sediments. The distributions of total organic carbon (TOC) in surface sediments are presented in Figure 2. The concentration of TOC varied from 7.25 to $65.542 \mathrm{~g} \mathrm{~kg}^{-1}$ with a mean of $36.37 \mathrm{~g} \mathrm{~kg}^{-1}$, and the highest concentration was found at DLNE-5, while the lowest concentration was found at DLNE1. Burns et al. [49] reported that the total organic carbon was highest in mixing zone where the processes of flocculation were maximums. DLNE-5 is located at the mouth of Haolai River inflows, and the high percentage of organic carbon found here would be probably due to: the following primary productivity input terrestrial organic matter, preferential decomposition, and grazing by benthic organisms were dominated in estuary of Haolai River. The sedimentological characteristics in the estuary of Haolai River were much dependent upon the combination of physical forces such as runoff, currents, and waves $[50,51]$. The concentrations of $\mathrm{HM}, \mathrm{HA}$, and FA in the lake sediments were detected 


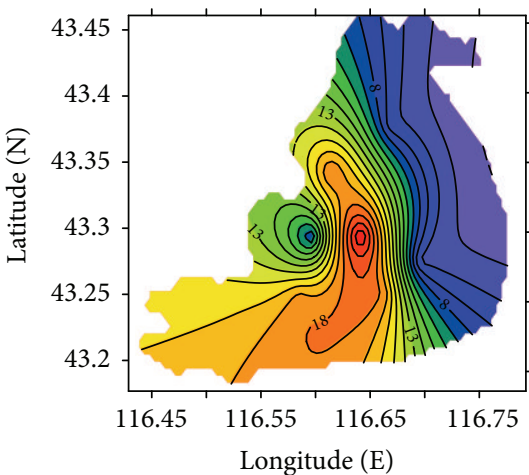

$\mathrm{HM}$

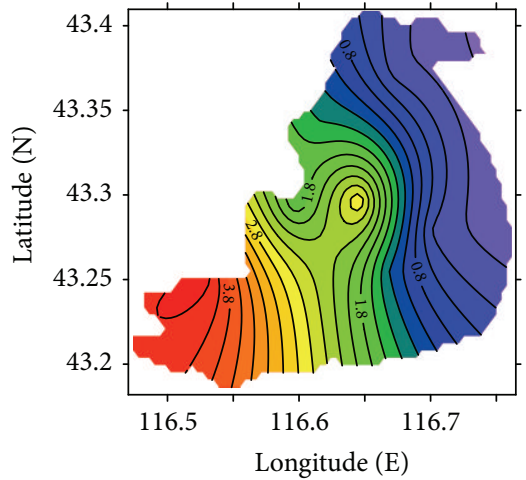

FA

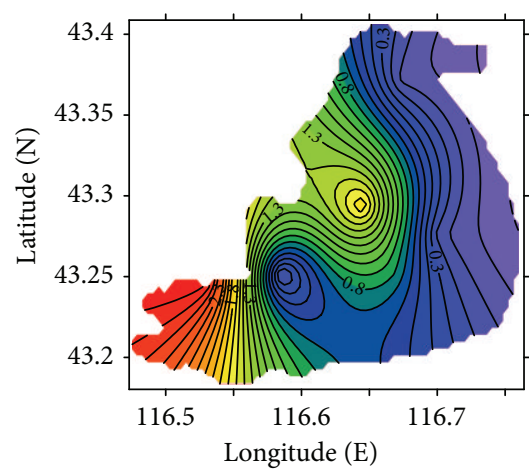

LCFA

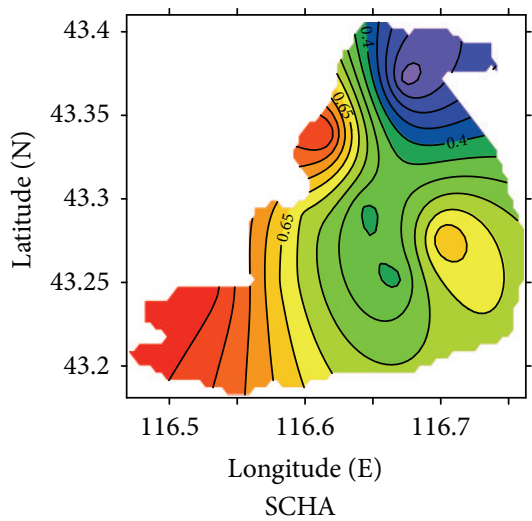

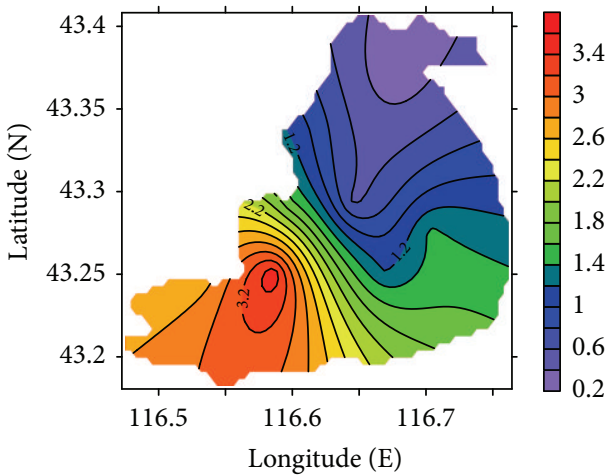

HA

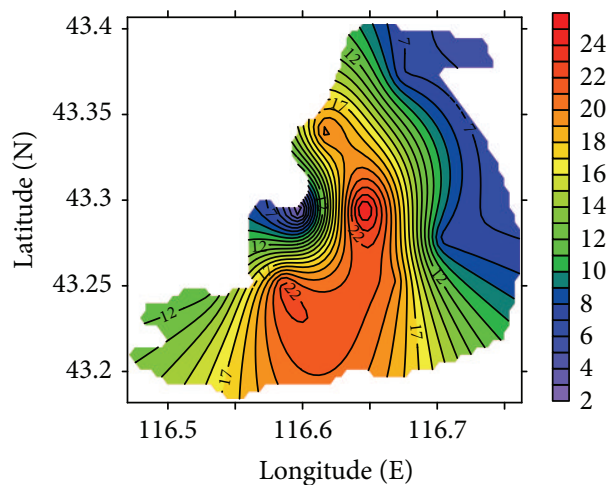

TOC

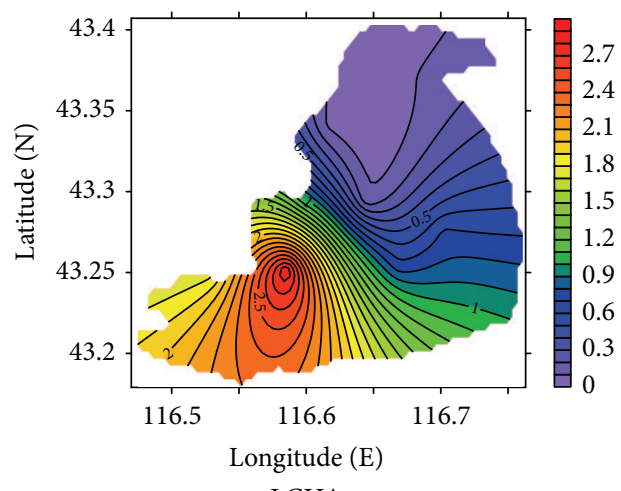

LCHA

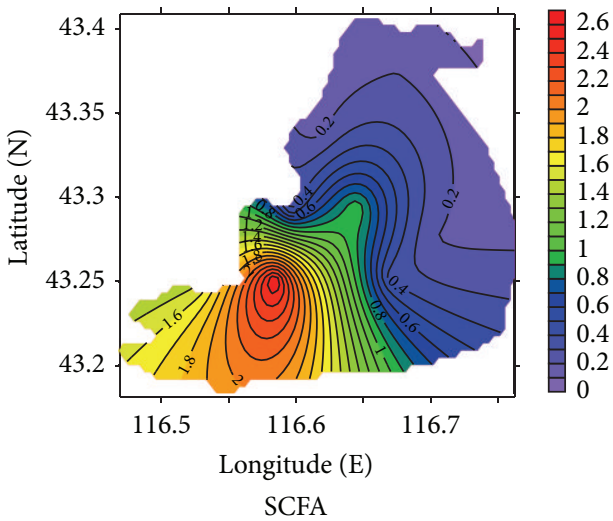

Figure 2: Distribution of HM, HA, FA, and different fractions of organic carbon in surface sediments from the Lake Dalinouer (HM: humins; HA: humic acid; FA: fulvic acid; TOC: total organic carbon; LCFA: loosely combined fulvic acid; LCHA: loosely combined humic acid; SCHA: stably combined humic acid; SCFA: stably combined fulvic acid). 
TABLE 2: The contents and percentages of different combined humus in surface sediment from the Lake Dalinouer.

\begin{tabular}{lccccccccc}
\hline & Total combined humus & \multicolumn{3}{c}{ Loosely combined humus } & \multicolumn{3}{c}{ Stably combined humus } & \multicolumn{2}{c}{ Tightly combined humus } \\
& $\mathrm{g} \mathrm{kg}^{-1}$ & $\mathrm{~g} \mathrm{~kg}^{-1}$ & $\%$ & $\mathrm{HA} / \mathrm{FA}$ & $\mathrm{g} \mathrm{kg}^{-1}$ & $\%$ & $\mathrm{HA} / \mathrm{FA}$ & $\mathrm{g} \mathrm{kg}^{-1}$ \\
\hline DLNE-1 & 7.0509 & 0.1657 & 2.42 & 1.22 & 0.3801 & 2.56 & 0.86 & 6.5051 \\
DLNE-2 & 20.5115 & 1.3424 & 6.59 & 0.07 & 1.0288 & 4.23 & 5.17 & 18.1403 & 97.6 \\
DLNE-3 & 25.5141 & 1.9315 & 7.87 & 0.07 & 1.4217 & 1.79 & 0.45 & 22.1609 & 93.4 \\
DLNE-4 & 11.2062 & 2.3224 & 21.4 & 0.85 & 0.9702 & 5.55 & 1.62 & 7.9136 & 78.6 \\
DLNE-5 & 22.5505 & 4.5438 & 21.6 & 0.06 & 2.3604 & 4.18 & 0.59 & 15.6463 & 78.4 \\
DLNE-6 & 23.8004 & 3.0591 & 14.4 & 18.5 & 3.2552 & 2.99 & 0.24 & 17.4861 \\
DLNE-7 & 20.0074 & 1.5581 & 7.93 & 0.91 & 0.8036 & 2.23 & 1.21 & 17.6457 & 85.6 \\
DLNE-8 & 7.6781 & 0.8751 & 11.7 & 5.21 & 0.9045 & 9.38 & 3.45 & 5.8985 & 92.1 \\
DLNE-9 & 13.3405 & 0.7595 & 6.09 & 8.94 & 0.8959 & 0.11 & 0.01 & 11.6851 & 88.2 \\
DLNE-10 & 23.3262 & 1.9188 & 8.35 & 2.97 & 1.2433 & 3.89 & 2.56 & 20.1641 & 93.9 \\
\hline
\end{tabular}

in the range of $6.40-58.16 \mathrm{~g} \mathrm{~kg}^{-1}, 0.27-3.5 \mathrm{~g} \mathrm{~kg}^{-1}$, and $0.27-$ $4.26 \mathrm{~g} \mathrm{~kg}^{-1}$, respectively, and the mean concentration of FA was about 1.5-3 times higher than that of HA. The fraction HA accounted for about $6 \%$ of the total organic matter in the sediment, whereas the FA was the second most abundant fraction in all sediment samples, accounted for about $15 \%$ of the total organic matter. It has been verified $[52,53]$ that the predominance of FA fraction over HA fraction which isolated from different sorbing solids in the natural water. Water $\mathrm{pH}$ in Dalinouer Lake was high (mean $\mathrm{pH}$ value 9.5), and it is known that the formation of FA are favored in alkaline environments, all of this may be the main reason of our finding with the concentration of FA higher than that of HA. In addition, the high content of exchangeable bases in sediment might increase the intensity of the humification process.

The ratio of HA/FA has been used by Naidja [54] as an indicator of humus quality. In this study, the ratios of HA/FA ranged from 0.6 to 4.1 with a mean of 1.3 , and the high HA/FA values found in the sediments indicated a relatively poor humus quality. The total concentration of HS was found generally constant. The highest store of loosely combined fulvic acid in surface sediment was found in DLNE-5 with a value of $2.78 \mathrm{~g} \mathrm{~kg}^{-1}$, both the loosely combined humic acid and the stably combined fulvic acid had a largest concentration in DLNE-6, with concentrations of $2.72 \mathrm{~g} \mathrm{~kg}^{-1}$ and $2.90 \mathrm{~g} \mathrm{~kg}^{-1}$, respectively. The content of loosely combined humus, stable combined humus, and tightly combined humus accounted for $38.06 \sim 43.32 \%, 9.71 \sim 10.84 \%$, and $46.61 \sim 52.23 \%$ in the heavy organic carbon fractions, respectively, and the general trend was tightly combined humus > loosely combined humus $>$ stable combined humus. HM was the dominate fraction of HS in surface sediment, accounted for about $80 \%$ of the total humic substance. The estimated organic $\mathrm{N}$ concentrations of the ten sites sampled from Dalinouer Lake ranged from $8.02 \mathrm{~g} \mathrm{~kg}^{-1}$ to $0.30 \mathrm{~g} \mathrm{~kg}^{-1}$, and the mean concentration was $3.28 \mathrm{~g} \mathrm{~kg}^{-1}$ (shown in Figure 2).

Overall, higher concentrations of TOC, ON, HM, HA, and FA occurred in surface sediment collected from the southwest of the Lake Dalinouer than those in other zones, and all measured concentrations in the surface sediment demonstrated a decreasing trend from southwest to northeast of the studied lake. These findings came with two qualifications. First, in sediments with a permanent deposition of organic matter, microbial activity led to a characteristic layering that reflected the sequence of electron acceptors according to the thermodynamic properties of the corresponding redox processes. The humification degree of phytoplankton, hydrobios, and autochthonous organic matter in surface sediment had a direct correlation with depth-related changes of water $[5,55]$. It is possible that in deepwater, oxygen was consumed within a few millimeters, and anaerobic respiration and fermentation processes were responsible for the degradation and mineralization of organic matter. On the contrary, in shallow water, oxygen originated form atmosphere could easily access the water-sediment interface, and the redox and degradation processes in the upper strata of lake sediment were active and sufficient. However, the fact that the amount of exogenous organic matter input overlarge and deposited at a high rate, could lead to incomplete decomposition of organic matter, which resulted in high content of total organic carbon in surface sediment form lakeside zone. Second, the time of sample collection only represented part of one season: late summer before many leaves fell from deciduous trees. Over the course of a year, variable inputs such as leaf fall, runoff from rain, and snowmelt could affect the organic matter concentrations of the supply-river and Dalinouer Lake.

Classifying the HS isolated from sedimentary organic matter into three types of combined humus (loosely, stably, and tightly humus) had proved to be useful in studying the relationship between organic carbon and availability of sediment nutrients [56]. In this study, the tightly combined humus, the most stable of all combined humus fractions, accounted for roughly over $80 \%$ of all three fractions (Table 2). The proportion of the stable fraction combined humus was higher than that in the loosely combined humus in the surface sediments from the Lake Dalinouer. Loosely combined humic acid and loosely combined fulvic acid had a similar spatial distribution in contents, but there was a large variation between stably combined humic acid and 
stably combined fulvic acid. The HA/FA ratio of the loosely combine humus varied obviously whereas that of the stably combined humus showed no marked change. The difference in chemical structures and activities of FA or HA with the fractions of loosely and stably combined might be the major reason for the different spatial distribution observed. It was also observed the marked differences in dissolved organic carbon concentrations among the sampled sites (shown in Figure 2), the lowest dissolved organic carbon was found in DLNE-1, and similar to total organic carbon contents, the highest dissolved organic carbon concentration was found in samples from DLNE-5 (almost three times higher than in DLNE-1), indicating an inflow of organic matter to its basin.

Light fraction was commonly referred to a plant-like and less stable fraction with high carbon concentration [57], and it has been considered as a dynamic fraction which reflects in short term shifts in soil organic matter storage and correlates well with the rate of $\mathrm{N}$ mineralization [58]. Heavy fraction, which is associated with clay and silt, is a more stable dense organo mineral fraction having lower carbon concentrations $[59,60]$. In this work, the $\mathrm{C}$ of the heavy fraction varied from 7.05 to $25.5 \mathrm{~g} \mathrm{~kg}^{-1}$, and which stock almost $98 \%$ of total organic carbon in surface sediment. The light organic $\mathrm{C}$ fraction presented the lowest values, only accounted for $2 \%$ of total organic carbon. This indicated that the clay and silt size fraction were the dominated aggregate size class in the surface sediment, the smaller particles had a narrower $\mathrm{C} / \mathrm{N}$ ratio, and $\mathrm{N}$ mineralization was much greater than that in the dissolved fraction. A possible reason for this observation is that the heavy fractions from sediment with extensive microaggregate structure should have narrow ratios and less accessible organic matter, and the organic matter was accumulated in the heavy fraction, while less $\mathrm{C}$ was associated with the light fraction.

Under anaerobic conditions, HS could act either as electron donors or electron acceptors via free radical intermediates and so participated in oxidation-reduction reaction. The $\mathrm{C} / \mathrm{N}$ ratios of organic matter were considered to be an indicator of the source of total organic matter in lake sediments. It had been reported that $\mathrm{C} / \mathrm{N}$ ratios were dependent on whether cellulose was present in the plants contributing organic matter to lake sediments [61]. The $\mathrm{C} / \mathrm{N}$ ratios in our study ranged from 4.7 to 24.2. Hedges et al. [62] reported that the average $\mathrm{C} / \mathrm{N}$ ratios for wood, leaf, and macrophyte material in the watershed area of Amazon River were 179, 24.1 and 39.4, respectively. The fact that high $\mathrm{C} / \mathrm{N}$ ratios were found in the organic matter of the surface sediments suggested that land plants were the major contributor to this organic matter fraction $[5,8,17,39]$.

An estimation of the humification degree was often based on monitoring of HS, humic acids, and fulvic acids isolated by extraction in alkaline solution. By investigating and comparing different approaches to the analysis of the humification degree in thoroughly described $[5,55]$, it was concluded that the concept of humification describes the transformation of organic matter to humus (humic substances). On this base, it was suggested that the degree of humification (HD) should be expressed in terms of the quantity of $\mathrm{HA}\left(\mathrm{C}_{\mathrm{HA}}\right)$ as a fraction of the total amount of $\mathrm{HA}$ and $\mathrm{FA}\left(\mathrm{C}_{\mathrm{HA}+\mathrm{FA}}\right)$.

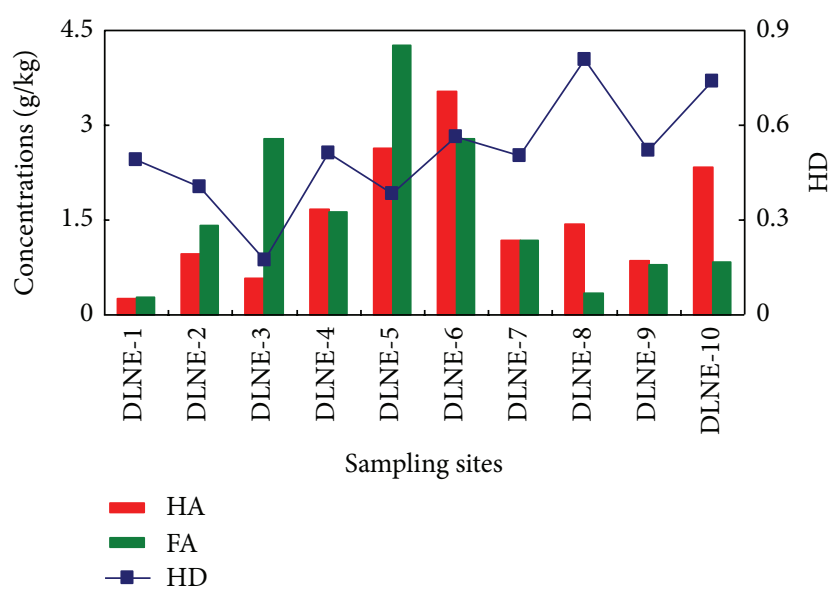

Figure 3: The distributions of HD, HA, and FA in Dalinouer Lake sediments.

Figure 3 illustrated the degree of humification in Dalinouer Lake. It was evident that the lowest humification was obtained in DLNE-3 with a HD value of 0.17 . The highest degree of humification was found in the eastern part of lake (DLNE8); about $81 \%$ of HA in total amount of HA and FA could be accounted for. It was possible that the degree of humification observed is related with both the origin of the organic matter and the local prevalence of anaerobic conditions. High degree of humification can be also associated with higher values of $\mathrm{C} / \mathrm{H}, \mathrm{C} / \mathrm{O}$, and $\mathrm{C} / \mathrm{N}$ atomic ratios due to decreased acid, carbohydrate, and amino acid/protein content [5].

\subsection{The Vertical Variation of Organic Carbon in Sediment} Core. Table 3 showed the concentrations of organic carbon, nitrogen, and phosphorus in the sediment cores from Dalinouer Lake, the concentration of TOC in DLNE-3 core was obviously higher than that of in DLNE-8, and this might be related with a slower deposition of hydrophyte and microorganisms under anaerobic conditions. DLNE-3 is located at the deep water zone, anoxic, or oxygen depleted, and environments may favor the accumulation of organic matter. At the $0 \sim 24 \mathrm{~cm}$ in the DLNE- 8 sediment core, the concentrations of ON, SCOC, LCHA, and HA were higher than those of in DLNE-3, and the other fractions of organic carbon were lower than those of in DLNE- 8 core, suggested that water depth and biomass were important in affecting factors which may govern the distribution of the different forms of organic carbon in sediments. In the DLNE-3 core sediments, HM was always the dominant fraction (36.10$54.37 \mathrm{~g} \mathrm{~kg}^{-1}$, mean value $\left.46.29 \mathrm{~g} \mathrm{~kg}^{-1}\right)$ followed by FA $(0.92-$ $\left.8.67 \mathrm{~g} \mathrm{~kg}^{-1}\right)$ and HA $\left(0.02-1.17 \mathrm{~g} \mathrm{~kg}^{-1}\right)$ (Figure 4). The same trends were also observed in the DLNE-8 core (Figure 4). HA concentrations in the surface sediments at DLNE-8 were higher that at the DLNE-3 stations; this high HA content between 0 and $5 \mathrm{~cm}$ in the NLNE- 8 sediment core occurred, while the concentration of the other HS fractions was decreasing.

Water was one of the most important constituents of microorganisms and was also a crucial solvent contributed 
TABLE 3: Speciation concentration of organic carbon, N, and P in the sediment cores from Dalinouer Lake $\left(\mathrm{g} \mathrm{kg}^{-1}\right)$.

\begin{tabular}{lccccccccc}
\hline \multirow{2}{*}{ Parameters } & \multicolumn{2}{c}{ Min } & \multicolumn{4}{c}{ Mean } \\
& DLNE-3 & DLNE-8 & DLNE-8 $(\leq 24 \mathrm{~cm})$ & DLNE-3 & DLNE-8 & DLNE-8 $(\leq 24 \mathrm{~cm})$ & DLNE-3 & DLNE-8 & DLNE-8 ( $\leq 24 \mathrm{~cm})$ \\
\hline OP & 0.063 & 0.044 & 0.044 & 0.141 & 0.059 & 0.057 & 0.181 & 0.081 & 0.075 \\
ON & 0.135 & 1.508 & 1.508 & 0.240 & 1.923 & 2.033 & 0.386 & 2.556 & 2.556 \\
TP & 1.279 & 0.985 & 1.107 & 1.624 & 1.155 & 1.214 & 2.192 & 1.309 & 1.309 \\
TN & 3.141 & 1.597 & 1.597 & 4.904 & 2.015 & 2.116 & 8.149 & 2.636 & 2.636 \\
RW & 0.547 & 0.236 & 0.419 & 0.612 & 0.586 & 0.611 & 0.730 & 0.797 & 0.797 \\
LFOC & 0.269 & 0.133 & 0.150 & 0.462 & 0.525 & 0.522 & 0.640 & 1.090 & 1.026 \\
HFOC & 37.324 & 15.896 & 16.431 & 49.538 & 21.207 & 22.797 & 59.431 & 30.171 & 30.171 \\
TOC & 37.788 & 16.167 & 16.749 & 50.000 & 21.732 & 23.319 & 59.856 & 30.744 & 30.744 \\
LCOC & 0.855 & 0.020 & 0.333 & 2.221 & 0.988 & 0.602 & 4.090 & 5.490 & 0.970 \\
SCOC & 0.049 & 0.255 & 0.255 & 1.486 & 1.427 & 1.295 & 5.981 & 2.209 & 2.034 \\
TCOC & 36.100 & 10.457 & 14.958 & 46.292 & 19.317 & 21.423 & 54.371 & 28.080 \\
LCHA & 0.007 & 0.049 & 0.049 & 0.192 & 0.702 & 0.344 & 0.632 & 3.254 & 28.080 \\
SCHA & 0.013 & 0.195 & 0.195 & 0.385 & 0.747 & 0.710 & 0.699 & 1.401 & 0.976 \\
LCFA & 0.357 & 0.081 & 0.081 & 2.030 & 0.807 & 0.366 & 4.045 & 5.103 & 1.359 \\
SCFA & 0.036 & 0.255 & 0.255 & 1.782 & 0.762 & 0.746 & 5.447 & 1.448 & 0.873 \\
HM & 36.100 & 10.457 & 14.958 & 46.292 & 19.317 & 21.381 & 54.371 & 28.080
\end{tabular}

OP: organic phosphorus; ON: organic nitrogen; RW: rate of water content; LFOC: light fraction organic carbon; HFOC: heavy fraction organic carbon; LCOC: loosely combined organic carbon; SCOC: stably combined organic carbon; TCOC: tightly combined organic carbon; LCHA: loosely combined humic acid; LCFA: loosely combined fulvic acid; SCHA: stably combined humic acid; SCFA: stably combined fulvic acid.

to good dissolution of nutrients in the metabolism process of microbe. At $0 \sim 24 \mathrm{~cm}$ layer profile, the range of RW (rate of water contents) in DLNE-3 and DLNE-8 sediment core was $54-74 \%$ and $42-80 \%$, respectively; these appropriate rates of water content may be playing a role in promoting the activities of microorganisms. Exception for FA at DLNE-8 stations, the concentrations of other organic carbon forms presented decreasing trends in the sediment cores, which might be attributed to the degradation processes of microorganisms. Benthic microorganisms could utilize HS as energy and $\mathrm{N}$ sources in estuarine sediments [63], and the biomass of microorganism decreased with depth [35]. However, HS depletions with depth were not observed in the cores probably because of the poorer nutritional value of the sedimentary organic matter but also because of the episodic deposition events that disturbed the HS profiles.

The evolution of the relative proportion of the different HS fractions could provide further insights on the environmental processes involved in their formation and transformations. Among the HS fractions, HM accounted for 63.51-97.71\% of the sedimentary organic matter while, HA and FA comprised $0.05-9.24 \%$ and $0.32-14.49 \%$, respectively (Table 4). Although the values reported in the literature vary widely, Naik and Poutanen [64] in Baltic Sea sediments observed similar HS distributions. The present results showed that most of the sedimentary organic matters were made up of HS, mostly associated with the mineral matrix (i.e., humins) [6]. The proportion of humins in sediments depended upon a number of depositional and biogeochemical conditions [30], such as primary productivity, terrigenous inputs, water depth, sedimentation rate, grain size, oxygen concentration, and microbial activity. Those factors could all modulate the amount and the nature of the sedimentary organic matter. FA proportion fluctuated but exhibited no clear trend with depth. In contrast, HA proportions decreased with depth, suggested HA selective preservation with time in the sediments. HM proportions in sedimentary organic matter also generally decreased with depth in the sediment layers that appeared not to be disturbed in the deposition processes.

3.4. Assessment of Organic Sediment Index. The organic load was evaluated by the Organic Sediment Index (OSI) of Ballinger and McKee (1971) [65, 66], which was determined as the product of the percentage of organic carbon (OC wt\%) and the percentage of organic nitrogen $(\mathrm{ONwt} \%)$ in a dry sediment:

$$
\mathrm{OSI}=[\mathrm{OC} w \mathrm{t} \%] \times[\mathrm{ON} w \mathrm{t} \%],
$$

where [OC $w t \%]$ was defined as the ratio between the organic matter (\%) and 1.724, while [ON wt\%] was the value of total nitrogen multiplied by 0.95 .

The OSI had a potential range of minus ten $(-10)$ to plus eleven $(+11)$ which reflected the ecological status (in terms of organic loading) of a particular survey and/or station. This index was developed for the classification of sedimentary deposits affected or not by organic pollution in rivers, lakes and estuaries. Sediment assessment based on standards of organic index is shown in Table 5, and OSI values of all sediments are in Table 6 . The surface sediments of Dalinouer Lake are characterized by a relative low organic content (OSI value ranging from 0.001 to 0.30 ) and a degree of pollution 


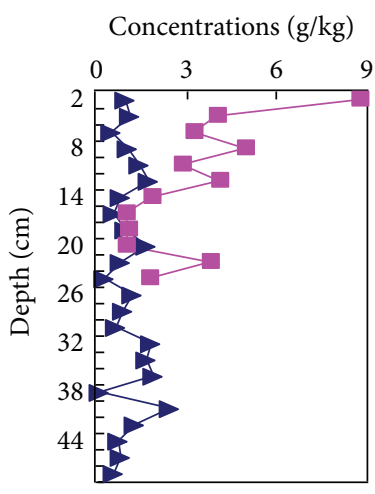

FA

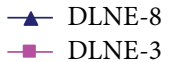

Concentrations (g/kg)

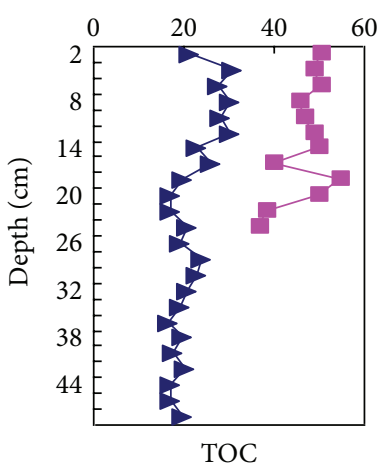

$\leftarrow$ DLNE-8

$\longrightarrow$ DLNE-8
- DLNE-3
Concentrations $(\mathrm{g} / \mathrm{kg})$

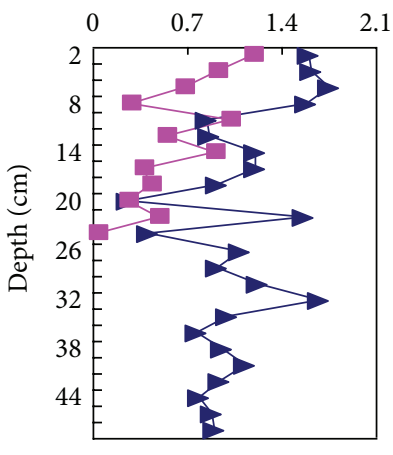

HA

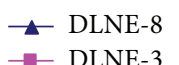

Concentrations (g/kg)

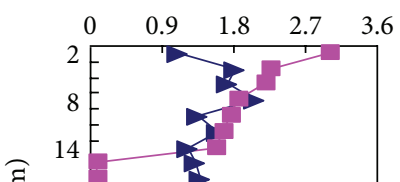

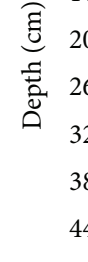$$
\text { . }
$$$$
\text { . }
$$
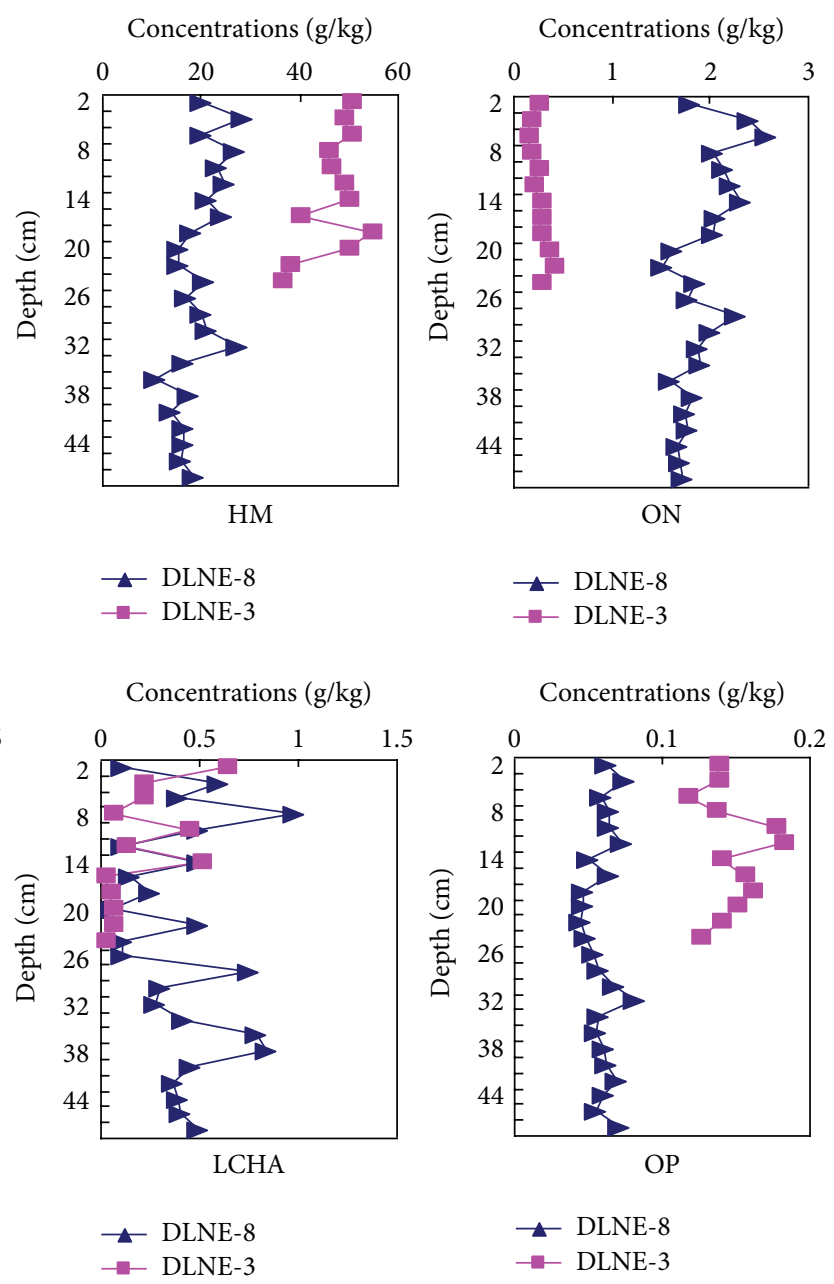

Figure 4: Vertical distribution of Humic substances, organic N, organic P, and different fractions of organic carbon in the sediment core of DLNE-3 and DLNE-8 (HM: humins; HA: humic acid; FA: fulvic acid; ON: organic nitrogen; TOC: total organic carbon; SCOC: stably combined organic carbon; LCHA: loosely combined humic Acid; OP: organic phosphorus).

relatively small. However, the sediments from DLNE-5 and DLNE-6, displayed an abrupt increase of OSI value that may be in relation to other organic inputs.

One reason for the abrupt increase in OSI at site DLNE5 and DLNE- 6 might be the large quantities of industrial effluents discharging into the river from nearby industrial zone of Dalinouer Lake. Furthermore, in the same area, intense agricultural activity and the associated application of agrichemicals which were introduced into the river water might be also contributing to the high OSI value of sediments in sites DLNE-5 and DLNE-6. Sediments of DLNE5 and DLNE-6, represent deep lake sampling, where anoxic conditions prevail. According to Neufeld and Hermann [67], anoxic conditions may accelerate the concentration of organic material, and therefore increasing the OSI value. Site DLNE-5 may also be influenced by waterborne materials, which were steadily conveyed by the river.

It was also noted a significant and strong positive correlation $\left(r^{2}>0.78, P<0.05\right)$ among total organic carbon, total nitrogen, total phosphorus, organic phosphorus, and organic nitrogen concentrations in the studied lake (Figure 5). Total organic carbon increased with the total nitrogen, and total phosphorus contents increased in lake surface sediments, which may indicate that the content of total organic carbon and the redox environment had a direct effect on the decomposition of organic nitrogen and the transformation of total phosphorus into orthophosphate in surface sediments [68, 69]. Nitrogen accumulates in sediments through numerous mechanisms, such as adsorption onto clay and soil organic matter, precipitation of nitrogen-containing organic matter, and mineralization; by heterotrophic bacteria. Different pools of nitrogen may reach the sediment and became the sources of nitrogen that were identified in soil organic matter and humic substances [70].

\section{Conclusion}

The results of the present study showed a high spatial heterogeneity of organic nitrogen, total organic carbon, and the different fractions of humus in Lake Dalinouer. The spatial differences may be related to the discharge of surrounding rivers and with varying hydrological and geochemical 
TABLE 4: Percentages of total organic matter defined as fulvic acids (FA), humic acids (HA), and humins (HM) in the Dalinouer Lake sediment cores.

\begin{tabular}{|c|c|c|c|c|}
\hline Location & Depth $(\mathrm{cm})$ & $\% \mathrm{HA}$ & $\% \mathrm{FA}$ & $\% \mathrm{HM}$ \\
\hline \multirow{12}{*}{ DLNE-3 } & 2 & 1.95 & 14.49 & 83.56 \\
\hline & 4 & 1.71 & 7.43 & 90.86 \\
\hline & 6 & 1.22 & 5.86 & 92.91 \\
\hline & 8 & 0.51 & 9.71 & 89.74 \\
\hline & 10 & 2.01 & 5.59 & 92.31 \\
\hline & 12 & 1.01 & 7.58 & 91.41 \\
\hline & 14 & 1.69 & 3.46 & 94.38 \\
\hline & 16 & 0.86 & 2.33 & 96.08 \\
\hline & 18 & 0.71 & 1.78 & 97.41 \\
\hline & 20 & 0.48 & 1.81 & 97.71 \\
\hline & 22 & 1.12 & 8.82 & 90.06 \\
\hline & 24 & 0.05 & 4.41 & 95.51 \\
\hline \multirow{24}{*}{ DLNE-8 } & 2 & 7.47 & 4.98 & 92.75 \\
\hline & 4 & 5.22 & 3.44 & 91.33 \\
\hline & 6 & 7.89 & 1.99 & 90.12 \\
\hline & 8 & 5.19 & 3.26 & 91.51 \\
\hline & 10 & 3.59 & 6.02 & 90.38 \\
\hline & 12 & 2.81 & 5.67 & 91.53 \\
\hline & 14 & 5.29 & 3.59 & 91.12 \\
\hline & 16 & 4.57 & 2.17 & 93.26 \\
\hline & 18 & 4.69 & 4.58 & 90.61 \\
\hline & 20 & 1.45 & 9.51 & 89.04 \\
\hline & 22 & 9.24 & 4.67 & 86.09 \\
\hline & 24 & 1.87 & 0.96 & 97.07 \\
\hline & 26 & 5.58 & 6.08 & 88.34 \\
\hline & 28 & 3.83 & 3.71 & 83.57 \\
\hline & 30 & 5.34 & 2.58 & 92.08 \\
\hline & 32 & 5.49 & 5.79 & 88.71 \\
\hline & 34 & 5.21 & 8.74 & 86.05 \\
\hline & 36 & 4.69 & 11.6 & 63.51 \\
\hline & 38 & 4.82 & 0.32 & 89.72 \\
\hline & 40 & 6.51 & 13.91 & 79.51 \\
\hline & 42 & 4.68 & 6.18 & 80.04 \\
\hline & 44 & 4.53 & 3.94 & 89.54 \\
\hline & 46 & 5.05 & 4.44 & 90.1 \\
\hline & 48 & 4.46 & 2.72 & 92.8 \\
\hline
\end{tabular}

TABLE 5: Classification of sediments based in standard organic indexes.

\begin{tabular}{lcc}
\hline Organic index & Grade & Type \\
\hline$<0.05$ & I & Clean \\
$\geq 0.05-<0.20$ & II & Relative clean \\
$\geq 0.20-<0.50$ & III & Slight pollution \\
$\geq 0.50$ & IV & Pollution \\
\hline
\end{tabular}

characteristics. The dominated fraction of humus in surface sediment was HM, and accounted for $74-94 \%$ of total organic carbon and $80-90 \%$ of HS. HA and FA were the productions of mineralization, in sediments, the water column conditions seemed to influence the mineralization and humification process, so, the lower concentrations of HA and FA were detected in shallow water zones where the organic matter is prone to mineralization. In the vertical variation, these HS showed decreasing trends with depth, which might correspond to the evolution in the sedimentary environment. Based on the data of OSI, the surface sediments of Dalinouer Lake were characterized by a relatively low organic content (OSI values ranged from 0.001 to 0.30 ), and the degree of pollution was relatively low. However, eutrophication and a sustained organic matter input are pointed as the major potential threat to Dalinouer Lake. 


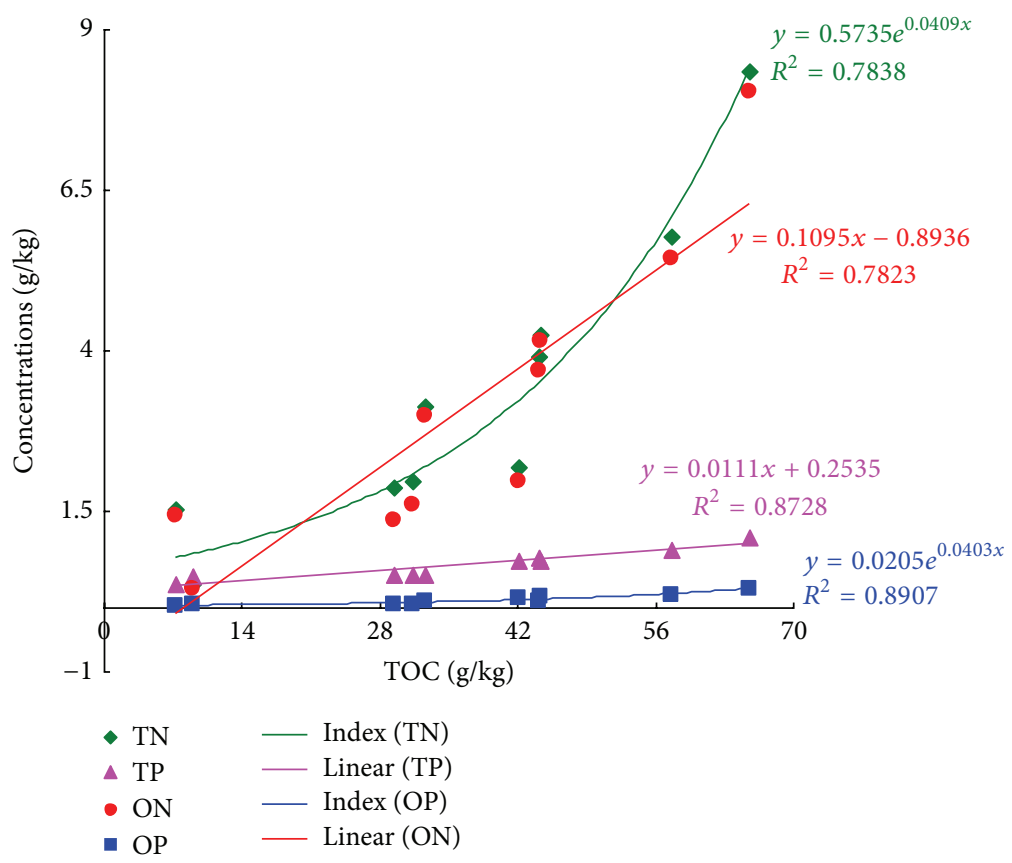

FIGURE 5: The relationship among total organic carbon, total phosphorus, total nitrogen, organic nitrogen and organic phosphorus concentrations in the studied lake.

TABLE 6: OSI values of sediment samples from Dalinouer Lake.

\begin{tabular}{lccc}
\hline Sample site & OC wt\% & ON wt\% & OSI \\
\hline DLNE-1 & 4.21 & 0.00013 & 0.006 \\
DLNE-2 & 25.6 & 0.00036 & 0.094 \\
DLNE-3 & 25.8 & 0.00041 & 0.106 \\
DLNE-4 & 24.4 & 0.00019 & 0.048 \\
DLNE-5 & 38.1 & 0.00081 & 0.305 \\
DLNE-6 & 33.4 & 0.00054 & 0.181 \\
DLNE-7 & 18.9 & 0.00029 & 0.056 \\
DLNE-8 & 18.2 & 0.00015 & 0.029 \\
DLNE-9 & 5.21 & 0.00004 & 0.002 \\
DLNE-10 & 17.1 & 0.00013 & 0.023 \\
\hline
\end{tabular}

\section{Conflict of Interests}

The authors declare that there is no conflict of interests regarding the publication of this paper.

\section{Acknowledgments}

The authors acknowledged financial support of this work by the National Natural Science Foundation of China (Grant nos. 40863003). The authors were indebted to Qitu $\mathrm{Hu}$ and Dalinouer fishery Co., Ltd., for the continuing logistical support.

\section{References}

[1] G. Fiorentino, R. Spaccini, and A. Piccolo, "Separation of molecular constituents from a humic acid by solid-phase extraction following a transesterification reaction," Talanta, vol. 68 , no. 4 , pp. 1135-1142, 2006.

[2] S. Pflugmacher, C. Pietsch, W. Rieger, and C. E. W. Steinberg, "Dissolved natural organic matter (NOM) impacts photosynthetic oxygen production and electron transport in coontail Ceratophyllum demersum," Science of the Total Environment, vol. 357, no. 1-3, pp. 169-175, 2006.

[3] H. Hyung and J.-H. Kim, "Natural organic matter (NOM) adsorption to multi-walled carbon nanotubes: effect of NOM characteristics and water quality parameters," Environmental Science and Technology, vol. 42, no. 12, pp. 4416-4421, 2008.

[4] M. A. Vairavamurthy, D. Maletic, S. Wang, B. Manowitz, T. Eglinton, and T. Lyons, "Characterization of sulfur-containing functional groups in sedimentary humic substances by X-ray absorption near-edge structure spectroscopy," Energy and Fuels, vol. 11, no. 3, pp. 546-553, 1997.

[5] A. H. Rosa, M. L. Simões, L. C. De Oliveira, J. C. Rocha, L. M. Neto, and D. M. B. P. Milori, "Multimethod study of the degree of humification of humic substances extracted from different tropical soil profiles in Brazil's Amazonian region," Geoderma, vol. 127, no. 1-2, pp. 1-10, 2005.

[6] L. Tremblay and J.-P. Gagné, "Distribution and biogeochemistry of sedimentary humic substances in the St. Lawrence Estuary and the Saguenay Fjord, Québec," Organic Geochemistry, vol.38, no. 4, pp. 682-699, 2007.

[7] M. Klavinsd and E. Apsite, "Sedimentary humic substances from lakes in Latvia," Environment International, vol. 23, no. 6, pp. 783-790, 1997.

[8] M. Chernysheva and G. Badun, "Tritium label in studying sorption of humic substances by carbon based nanomaterials," European Journal of Chemistry, vol. 2, no. 1, pp. 61-64, 2011. 
[9] J. Vogl and K. G. Heumann, "Determination of heavy metal complexes with humic substances by HPLC/ICP-MS coupling using on-line isotope dilution technique," Fresenius' Journal of Analytical Chemistry, vol. 359, no. 4-5, pp. 438-441, 1997.

[10] J. Kang, Z. Q. Zhang, and J. J. Wang, "Influence of humic substances on bioavailability of $\mathrm{Cu}$ and $\mathrm{Zn}$ during sewage sludge composting," Bioresource Technology, vol. 102, no. 17, pp. 80228026, 2011.

[11] L. F. Ping, C. R. Zhang, Y. H. Zhu et al., "Imidacloprid adsorption by soils treated with humic substances under different $\mathrm{pH}$ and temperature conditions," African Journal of Biotechnology, vol. 9, no. 13, pp. 1935-1940, 2010.

[12] Y. Yang, L. Shu, X. L. Wang, B. S. Xing, and S. Tao, "Mechanisms regulating bioavailability of phenanthrene sorbed on a peat soil-origin humic substance," Environmental Toxicology \& Chemistry, vol. 31, no. 7, pp. 1431-1437, 2012.

[13] G. R. Aiken, D. M. McKnight, R. L. Wershaw, and P. MacCarthy, Eds., Humic Substances in Soil, Sediment, and Water, WildyInterscience, New York, NY, USA, 1985.

[14] T. Shinozuka, M. Shibata, and T. Yamaguchi, "Molecular weight characterization of humic substances by MALDI-TOF-MS," Journal of the Mass Spectrometry Society of Japan, vol. 52, no. 1, pp. 29-32, 2004.

[15] M. Schnitzer, "Soil organic matter-the next 75 years," Soil Science, vol. 151, no. 1, pp. 41-58, 1991.

[16] R. Baigorri, M. Fuentes, G. González-Gaitano, J. M. GarćiaMina, G. Almendros, and F. J. González-Vila, "Complementary multianalytical approach to study the distinctive structural features of the main humic fractions in solution: gray humic acid, brown humic acid, and fulvic acid," Journal of Agricultural and Food Chemistry, vol. 57, no. 8, pp. 3266-3272, 2009.

[17] G. Abate and J. C. Masini, "Acid-base and complexation properties of a sedimentary humic acid: a study on the Barra Bonita reservoir of Tietê River, São Paulo State, Brazil," Journal of the Brazilian Chemical Society, vol. 12, no. 1, pp. 109-116, 2001.

[18] H. V.-M. Nguyen, J.-K. Shin, and J. Hur, "Multivariate analysis for spatial distribution of dissolved organic matters in a large river-type dam reservoir," Environmental Monitoring and Assessment, vol. 183, no. 1-4, pp. 425-436, 2011.

[19] Z. Liang, J.-X. Liu, and J. Li, “Decomposition and mineralization of aquatic humic substances (AHS) in treating landfill leachate using the Anammox process," Chemosphere, vol. 74, no. 10, pp. 1315-1320, 2009.

[20] Y. L. Zhang, Y. Yin, X. H. Liu et al., "Spatial-seasonal dynamics of chromophoric dissolved organic matter in Lake Taihu, a large eutrophic, shallow lake in China," Organic Geochemistry, vol. 42, no. 5, pp. 510-519, 2011.

[21] A. Leeben, A. Heinsalu, T. Alliksaar, and J. Vassiljev, "Highresolution spectroscopic study of pore-water dissolved organic matter in Holocene sediments of Lake Peipsi (Estonia/Russia)," Hydrobiologia, vol. 646, no. 1, pp. 21-31, 2010.

[22] E. R. Carvalho, L. Martin-Neto, D. M. B. P. Milori, J. C. Rocha, and A. H. Rosa, "Interactions of chlorine with tropical aquatic fulvic acids and formation of intermediates observed by fluorescence spectroscopy," Journal of the Brazilian Chemical Society, vol. 15, no. 3, pp. 421-426, 2004.

[23] J. Zhong, R. L. Sleighter, E. Salmon, G. A. McKee, and P. G. Hatcher, "Combining advanced NMR techniques with ultrahigh resolution mass spectrometry: a new strategy for molecular scale characterization of macromolecular components of soil and sedimentary organic matter," Organic Geochemistry, vol. 42, no. 8, pp. 903-916, 2011.
[24] M. A. P. Pérez, P. Moreira-Turcq, H. Gallard, T. Allard, and M. F. Benedetti, "Dissolved organic matter dynamic in the Amazon basin: sorption by mineral surfaces," Chemical Geology, vol. 286, no. 3-4, pp. 158-168, 2011.

[25] K. Tsuda, H. Mori, D. Asakawa et al., "Characterization and grouping of aquatic fulvic acids isolated from clear-water rivers and lakes in Japan," Water Research, vol. 44, no. 13, pp. 38373846, 2010.

[26] M. Giovanela, J. S. Crespo, M. Antunes et al., "Chemical and spectroscopic characterization of humic acids extracted from the bottom sediments of a Brazilian subtropical microbasin," Journal of Molecular Structure, vol. 981, no. 1-3, pp. 111-119, 2010.

[27] J. M. De la Rosa, J. A. González-Pérez, R. González-Vázquez et al., "Use of pyrolysis/GC-MS combined with thermal analysis to monitor $\mathrm{C}$ and $\mathrm{N}$ changes in soil organic matter from a Mediterranean fire affected forest," Catena, vol. 74, pp. 296-303, 2008.

[28] J. M. De la Rosa, J. A. González-Pérez, F. J. González-Vila, H. Knicker, and M. F. Araújo, "Molecular composition of sedimentary humic acids from South West Iberian Peninsula: a multiproxy approach," Organic Geochemistry, vol. 42, no. 7, pp. 791$802,2011$.

[29] O. Polvillo, J. A. González-Pérez, T. Boski, and F. J. GonzálezVila, "Structural features of humic acids from a sedimentary sequence in the Guadiana estuary (Portugal-Spain border)," Organic Geochemistry, vol. 40, no. 1, pp. 20-28, 2009.

[30] N. Calace, N. Cardellicchio, B. M. Petronio, M. Pietrantonio, and M. Pietroletti, "Sedimentary humic substances in the northern Adriatic sea (Mediterranean sea)," Marine Environmental Research, vol. 61, no. 1, pp. 40-58, 2006.

[31] M. A. Browne, P. Crump, S. J. Niven et al., "Accumulation of microplastic on shorelines woldwide: sources and sinks," Environmental Science and Technology, vol. 45, no. 21, pp. 91759179, 2011.

[32] L.-Y. Liu, J.-Z. Wang, J.-W. Qiu, Y. Liang, and E. Y. Zeng, "Persistent organic pollutants in coastal sediment off South China in relation to the importance of anthropogenic inputs," Environmental Toxicology and Chemistry, vol. 31, no. 6, pp. 11941201, 2012.

[33] F. K. Achard, "Chemische untersuchung des torfs," Crell's Annales de Chimie, vol. 2, pp. 391-403, 1786.

[34] J. Xu, J. Wu, and Y. He, Eds., Functions of Natural Organic Matter in Changing Environment, Zhejiang University Press, Spinger, China, 2012.

[35] C.-L. Tong, W.-J. Zhang, H.-Q. Wang, G.-Y. Tang, G.-R. Yang, and J.-S. Wu, "Relationship between organic carbon and water content in four type wetland sediments in Sanjiang plain," Environmental Science, vol. 26, no. 6, pp. 38-42, 2005 (Chinese).

[36] G.-J. Li, Y.-Z. Lü, and B.-G. Li, "Effects of different managements on soil humic acid structural features in chestnut soil on typical leymus chinensis steppe, Inner Mongolia, China," Spectroscopy and Spectral Analysis, vol. 29, no. 6, pp. 1508-1511, 2009 (Chinese).

[37] S. R. Zhang, J. Wen, T. Li et al., "Soil carbon fractions of restored lands in Liusha River Valley, Sichuan," Ecological Engineering, vol. 40, pp. 27-36, 2012.

[38] W. M. Chen, X. F. Huang, and W. P. Zhou, Lake Ecosystem Observation Method, China Environmental Science Press, 2005.

[39] A. Kappler, R. Ji, B. Schink, and A. Brune, "Dynamics in composition and size-class distribution of humic substances in profundal sediments of lake constance," Organic Geochemistry, vol. 32, no. 1, pp. 3-10, 2001. 
[40] M. B. Da Cunha-Santino and I. B. Júnior, "Humic substance mineralization in a tropical oxbow lake (São Paulo, Brazil)," Hydrobiologia, vol. 468, pp. 33-43, 2002.

[41] S. W. Chang Chien, C. Y. Chen, J. H. Chang, S. H. Chen, M. C. Wang, and M. R. Mannepalli, "Sorption of toluene by humic acids derived from lake sediment and mountain soil at different pH," Journal of Hazardous Materials, vol. 177, no. 1-3, pp. 10681076, 2010.

[42] C. Wang, J. Qian, Z.-Y. Guo, L. Zhao, and X.-C. Li, "Vertical distributions of phosphorus fractions in sediments of three typical shallow urban lakes in P.R. China," Polish Journal of Environmental Studies, vol. 17, no. 1, pp. 155-162, 2008.

[43] S. R. Wang, L. X. Jiao, X. C. Jin, and D. L. Niu, "Characteristics of organic nitrogen fractions in sediments of the shallow lakes in the middle and lower reaches of the Yangtze River area in China," Water and Environment Journal, vol. 26, pp. 473-481, 2012.

[44] J. K. Whalen, P. J. Bottomley, and D. D. Myrold, "Carbon and nitrogen mineralization from light- and heavy-fraction additions to soil," Soil Biology and Biochemistry, vol. 32, no. 10, pp. 1345-1352, 2000.

[45] B. C. Liang, B. G. McConkey, J. Schoenau et al., "Effect of tillage and crop rotations on the light fraction organic carbon and carbon mineralization in Chernozemic soils of Saskatchewan," Canadian Journal of Soil Science, vol. 83, no. 1, pp. 65-72, 2003.

[46] B. Han, S. Q. Xu, H. L. Zhang, and F. Chen, "Effect of tillage practices on combined forms of humus and humus components," Journal of China Agricultural University, vol. 15, no. 1, pp. 72-78, 2010 (Chinese).

[47] H.-F. Mao, J. He, C.-W. Lü, Y. Liang, H.-L. Liu, and F.-J. Wang, "Characteristics of organic carbon forms in the sediment of Wuliangsuhai and Daihai Lakes," Environmental Science, vol. 32, no. 3, pp. 658-666, 2011 (Chinese).

[48] D. Champan, "Water quality assessments," in A Guide to the Use of Biota, Sediments, and Water in Environmental Monitoring, pp. 324-328, Chapman \& Hall, London, UK, 1992.

[49] K. A. Burns, G. Brunskill, D. Brinkman, and I. Zagorskis, "Organic carbon and nutrient fluxes to the coastal zone from the Sepik River outflow," Continental Shelf Research, vol. 28, no. 2, pp. 283-301, 2008.

[50] P. Van Santen, P. G. E. F. Augustinus, B. M. Janssen-Stelder, S. Quartel, and N. H. Tri, "Sedimentation in an estuarine mangrove system," Journal of Asian Earth Sciences, vol. 29, no. 4, pp. 566-575, 2007.

[51] J. Xu, "Grain-size characteristics of suspended sediment in the Yellow River, China," Catena, vol. 38, no. 3, pp. 243-263, 2000.

[52] E. Yamada, K. Doi, K. Okano, and Y. Fuse, "Simultaneous determinations of the concentration and molecular weight of humic substances in environmental water by gel chromatography with a fluorescence detector," Analytical Sciences, vol. 16, no. 2, pp. 125-129, 2000.

[53] H. Ma, H. E. Allen, and Y. Yin, "Characterization of isolated fractions of dissolved organic matter from natural waters and a wastewater effluent," Water Research, vol. 35, no. 4, pp. 985996, 2001.

[54] A. Naidja, P. M. Huang, D. W. Anderson, and C. van Kessel, "Fourier transform infrared, UV-visible, and X-ray diffraction analyses of organic matter in humin, humic acid, and fulvic acid fractions in soil exposed to elevated $\mathrm{CO}_{2}$ and $\mathrm{N}$ fertilization," Applied Spectroscopy, vol. 56, no. 3, pp. 318-324, 2002.
[55] M. Klavins, J. Sire, O. Purmalis, and V. Melecis, "Approaches to estimating humification indicators for peat," Mire and Peat, vol. 3, no. 3, pp. 1-15, 2009.

[56] C. Donisa, R. Mocanu, and E. Steinnes, "Distribution of some major and minor elements between fulvic and humic acid fractions in natural soils," Geoderma, vol. 111, no. 1-2, pp. 75-84, 2003.

[57] A. Golchin, J. M. Oades, J. O. Skjemstad, and P. Clarke, "Study of free and occluded particulate organic matter in soils by solid state ${ }^{13} \mathrm{C} \mathrm{CP} / \mathrm{MAS}$ NMR spectroscopy and scanning electron microscopy," Australian Journal of Soil Research, vol. 32, no. 2, pp. 285-309, 1994.

[58] Z. Tan, R. Lal, L. Owens, and R. C. Izaurralde, "Distribution of light and heavy fractions of soil organic carbon as related to land use and tillage practice," Soil and Tillage Research, vol. 92, no. 12, pp. 53-59, 2007.

[59] J. Hassink, "Density fractions of soil macroorganic matter and microbial biomass as predictors of C and N mineralization," Soil Biology and Biochemistry, vol. 27, no. 8, pp. 1099-1108, 1995.

[60] E. Barrios, R. J. Buresh, and J. I. Sprent, "Nitrogen mineralization in density fractions of soil organic matter from maize and legume cropping systems," Soil Biology and Biochemistry, vol. 28, no. 10-11, pp. 1459-1465, 1996.

[61] P. A. Meyers and R. Ishiwatari, "Lacustrine organic geochemistry-an overview of indicators of organic matter sources and diagenesis in lake sediments," Organic Geochemistry, vol. 20, no. 7, pp. 867-900, 1993.

[62] J. I. Hedges, W. A. Clark, P. D. Quay, J. E. Richey, A. H. Devol, and U. D. M. Santos, "Compositions and fluxes of particulate organic material in the Amazon River," Limnology \& Oceanography, vol. 31, no. 4, pp. 717-738, 1986.

[63] Z. Filip and J. J. Alberts, "Microbial utilization resulting in early diagenesis of salt-marsh humic acids," Science of the Total Environment, vol. 144, pp. 121-135, 1994.

[64] S. Naik and E. L. Poutanen, "Humic substances in Baltic Sea sediments," Oceanologica Acta, vol. 7, pp. 431-439, 1984.

[65] J. C. Rostan, C. Amoros, and J. Juget, "The organic content of the surficial sediment: a method for the study of ecosystems development in abandoned river channels," Hydrobiologia, vol. 148, no. 1, pp. 45-62, 1987.

[66] S. A. Hadjispyrou, A. Anagnostopoulos, K. Nicholson, M. K. Nimfopoulos, and K. M. Michailidis, "Correlation of the methylating capacity of river and marine sediments to their organic sediment index," Environmental Geochemistry and Health, vol. 20, no. 1, pp. 19-27, 1998.

[67] R. D. Neufeld and E. R. Hermann, "Heavy metal removal by acclimated activated sludge," Journal of the Water Pollution Control Federation, vol. 47, no. 2, pp. 310-329, 1975.

[68] H. B. Ma, J. M. Song, X. X. Lü, and H. M. Yuan, "Nitrogen forms and their functions in recycling of Bohai Sea sediments," Geochimica, vol. 32, no. 1, pp. 48-54, 2003 (Chinese).

[69] A. Trojanowska and P. Jezierski, "Phosphorus in sediments and pore waters of selected Polish dam reservoirs," Oceanological and Hydrobiological Studies, vol. 40, no. 2, pp. 72-85, 2011.

[70] H.-R. Schulten and M. Schnitzer, "The chemistry of soil organic nitrogen: a review," Biology and Fertility of Soils, vol. 26, no. 1, pp. $1-15,1998$. 

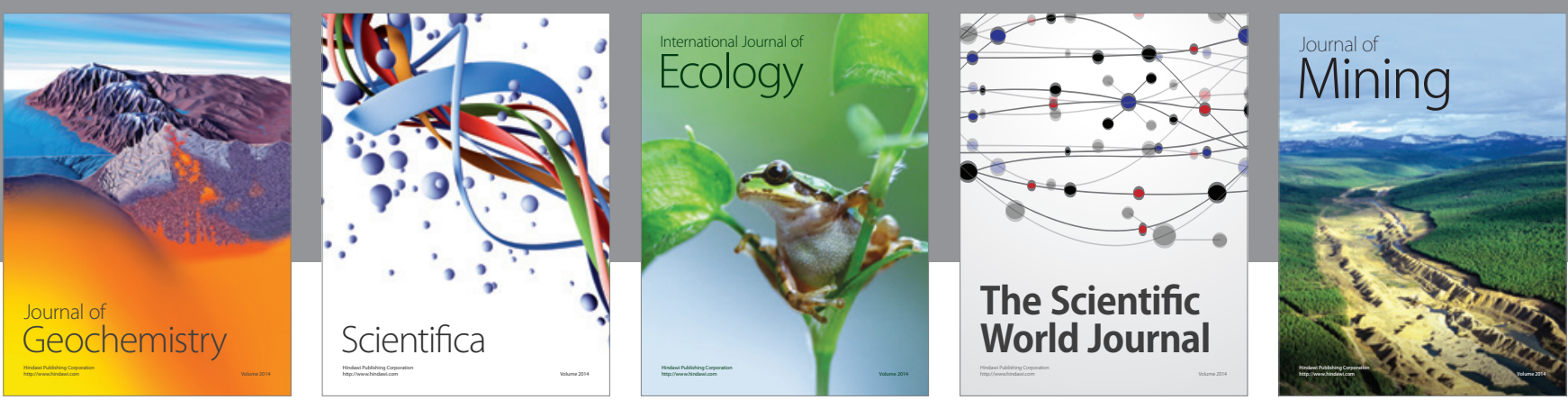

The Scientific World Journal
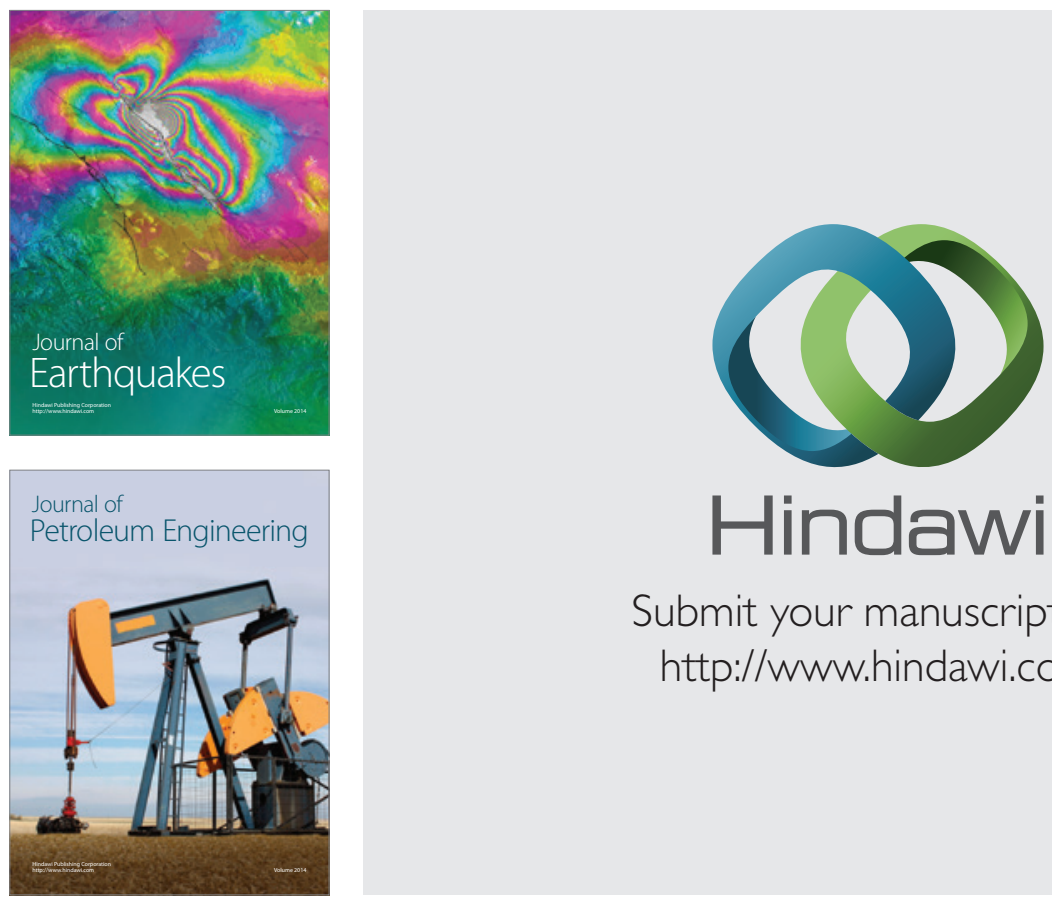

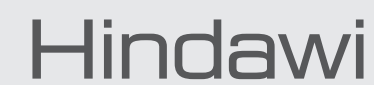

Submit your manuscripts at

http://www.hindawi.com
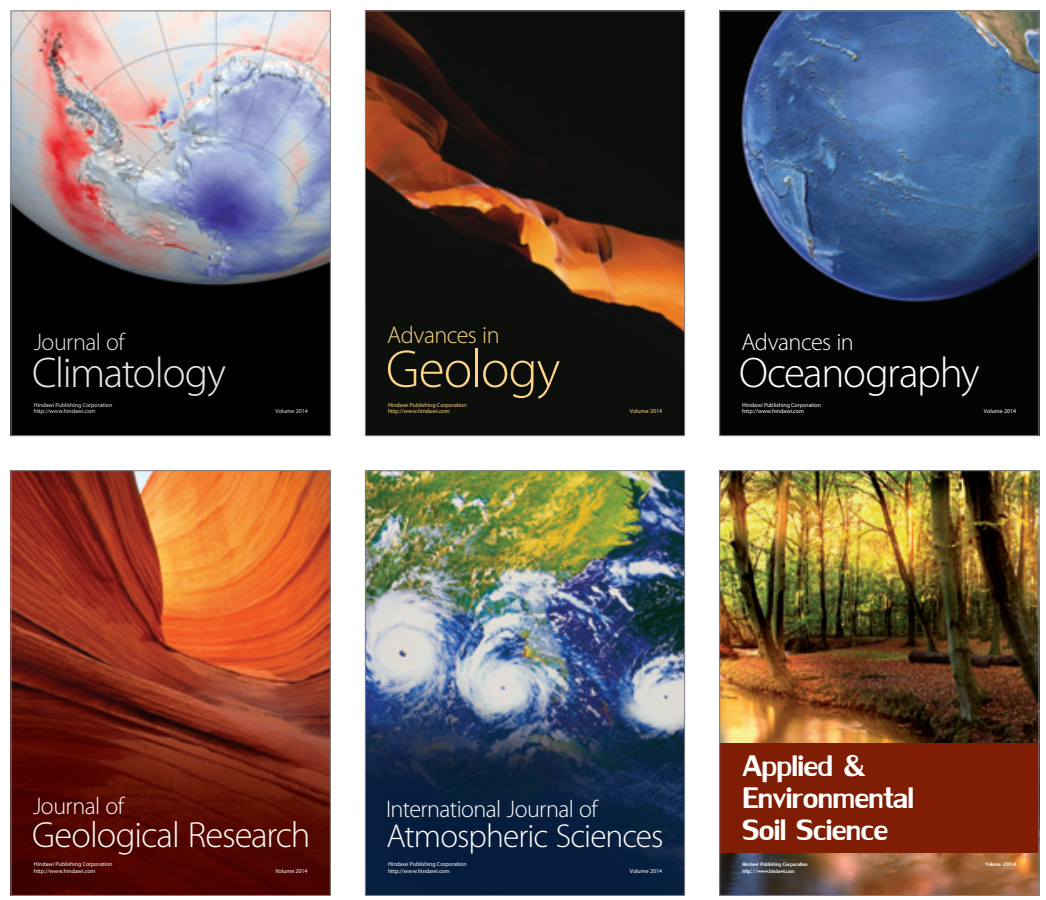
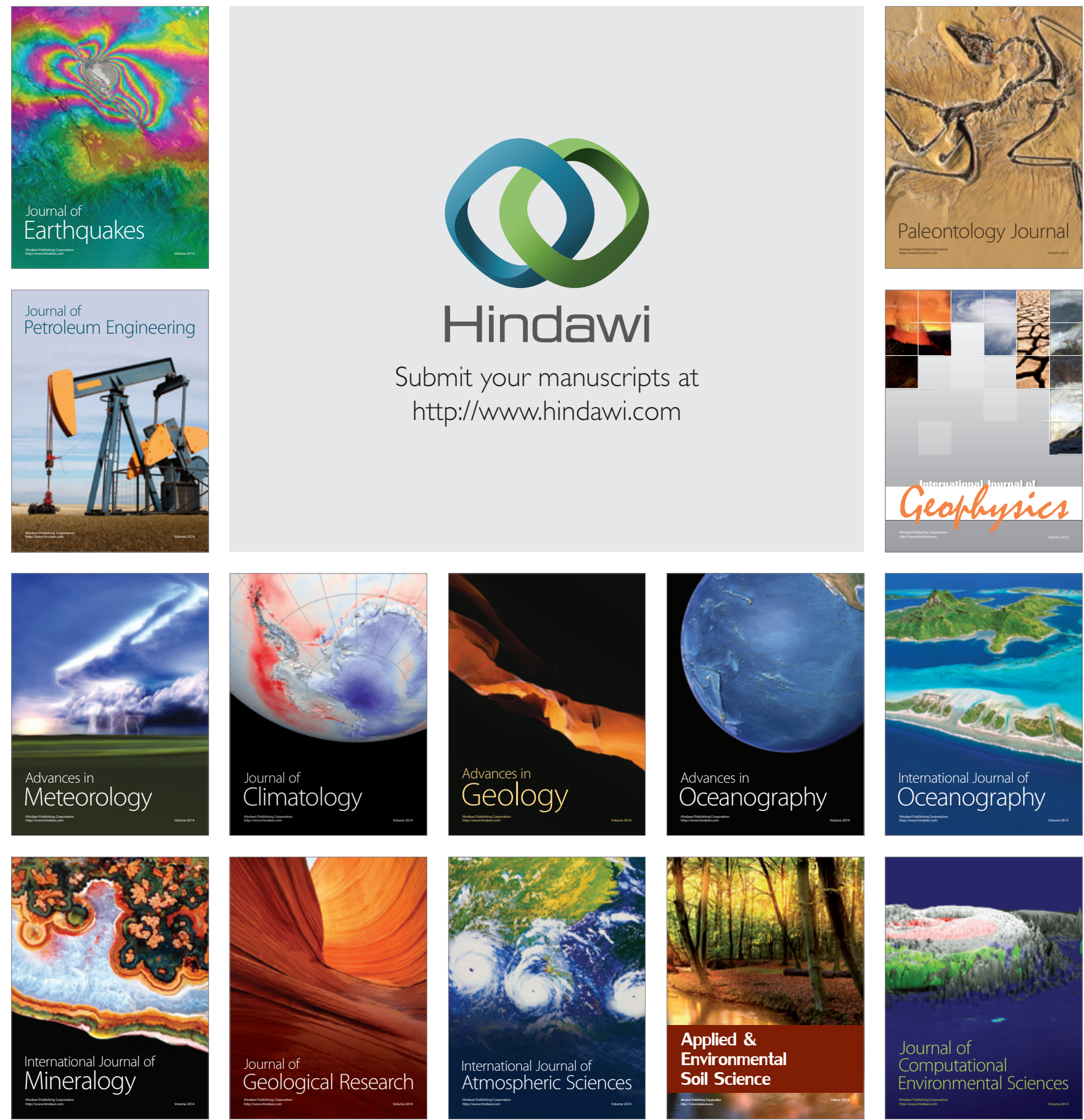